ISSN 1518-3483

Licenciado sob uma Licença Creative Commons

\title{
Avaliação da aprendizagem na Educação Básica: as pesquisas do estado da arte em questão $(1980-2007)^{1}$
}

Learning evaluation on the basic education:researches of the state of the art in question (1980-2007)

\section{Adolfo Ignacio Calderón ${ }^{[a]}$, Heloisa Poltronieri ${ }^{[b]}$}

[a] Doutor em Ciências Sociais pela Pontifícia Universidade Católica de São Paulo (PUC-SP), docente-pesquisador do Programa de Mestrado em Educação da Pontifícia Universidade Católica de Campinas (PUC-Campinas), Campinas, SP - Brasil, e-mail: adolfo.ignacio@puc-campinas.edu.br

[b] Mestranda em Educação pela Pontifícia Universidade Católica de Campinas (PUC-Campinas), bolsista da Coordenação de Aperfeiçoamento de Pessoal de Nível Superior (CAPES), Campinas, SP - Brasil, e-mail: helo_poltronieri@hotmail.com

\section{Resumo}

Este artigo tem por objetivo identificar e analisar os estudos existentes sobre o estado da arte focados na área da avaliação da aprendizagem da Educação Básica, visando a

1 Este artigo é a versão revisada, ampliada e reestruturada do texto intitulado A avaliação da aprendizagem à luz das pesquisas sobre o estado da arte (1980-2007), discutido no X Encontro de Pesquisa em Educação da Região Sudeste, promovido pela Associação Nacional de Pós-Graduação e Pesquisa em Educação (ANPEd), e no Fórum de Coordenadores de Pós-Graduação em Educação da Região Sudeste. 
compreender as principais contribuições e preocupações teórico-metodológicas da comunidade científica brasileira na área em questão. As referências de análise foram três grandes pesquisas estruturantes da compreensão da avaliação da aprendizagem como campo de conhecimento, que focam um período de 28 anos (1980 a 2008) (BARRETO; PINTO, 2001; SOUSA, 1994; ULER, 2010), complementadas por duas pesquisas que ressaltam especificidades da área (CANDAU; OSWALD, 1995; SOUSA, 2005). Analisando a produção científica dentro de uma linha de tempo, fica evidenciada a força do paradigma tecnicista nas décadas de 1970 e 1980, bem como as tentativas de sua superação no decorrer da década de 1980 na direção de propostas formativas e emancipatórias. Na década de 1990, a preocupação dos pesquisadores deslocou-se das práticas avaliativas na escola, de cunho tecnicista, para a abordagem crítica das ideias, concepções, teorias e pressupostos da avaliação. Na primeira década do século XXI, constatou-se um direcionamento teórico que acenava para a hegemonia, no campo científico brasileiro, de um paradigma emancipatório, que tinha em seu cerne a avaliação da aprendizagem de forma processual, participativa e formativa. Contudo, as pesquisas demonstram o acentuado distanciamento entre os referenciais teóricos utilizados nas universidades (paradigma emancipatório) e a realidade das escolas públicas (paradigma tecnicista-tradicional).

Palavras-chave: Avaliação da aprendizagem. Estado da arte. Pesquisa em educação.

\section{Abstract}

This article intends to identify and to analyze studies about the State of the Art focused on the evaluation area in the basic education, trying to understand which are the main theoretical and methodological contributions and concerns of the Brazilian scientific community to this area. Three important researches, which focus a period of 28 years, from 1980 to 2008 (BARRETO; PINTO, 2001; SOUSA, 1994; ULER, 2010), complemented by two other studies that highlight particularities of the area (CANDAU; OSWALD, 1995; SOUSA, 2005) are the basis to comprehend learning evaluation as a field of knowledge. Analyzing the scientific production in a timeline, the power of the technicist paradigm during the 70's and the 80's is evident, as well as the attempts to overcome it during the 80 's in the direction of formative and emancipatory proposals. During the 90's, researchers' concerns move from the evaluative practices in the school, of technical approach, to a critical coverage of the ideas, concepts, theories and assumptions of the evaluation. Now, the first decade of this 
century, in the Brazilian scientific field, it's noticed a theoretical direction that points to the hegemony of an emancipatory paradigm, whose essence consists in a procedural, participatory and formative evaluation of learning. However, the studies show the great distance between theoretical references used in universities (emancipatory paradigm) and reality in public schools (technicist-traditional paradigm).

Keywords: Learning evaluation. State of the art. Education research.

\section{Introdução}

A avaliação da aprendizagem constitui um dos temas mais discutidos quando se trata de estudos sobre avaliação da educação no ensino básico no Brasil (BARRETO; PINTO, 2001). Existe vasta produção acadêmica acerca do assunto, que se expressa na forma de artigos publicados em revistas especializadas e periódicos, teses de doutoramento e dissertações de mestrado. Diante de tantas publicações, surge uma linha de pesquisa, baseada nos estudos do estado da arte ou estado do conhecimento, direcionada a realizar um balanço da produção acadêmica sobre o tema, com a finalidade de mapear aquilo que foi produzido, possibilitando a visualização das evoluções no campo do conhecimento, bem como as lacunas ainda existentes na área da avaliação da aprendizagem na Educação Básica.

No Brasil, produções do tipo estado da arte ganharam espaço no meio acadêmico em parcerias com organismos governamentais. O Instituto de Estudos e Pesquisas Educacionais Anísio Teixeira (Inep), no final da década de 1990, viabilizou a realização de estudos sobre o estado da arte em torno de diversos temas, como alfabetização, educação infantil, gestão da educação, formação de professores e educação superior, divulgados na Série Estado do Conhecimento, totalizando 11 fascículos. Estudos que se dedicam, especificamente, a analisar o estado da arte da avaliação da aprendizagem vêm sendo produzidos na comunidade científica brasileira desde os primeiros anos da década de 1990, destacando-se a 
preocupação dos pesquisadores em conhecer o estágio de desenvolvimento acadêmico desse tema.

Buscando contribuir com os esforços em compreender a evolução desse campo do conhecimento, pretende-se, por meio deste artigo, estudar as pesquisas existentes sobre o estado da arte focadas na área da avaliação da aprendizagem na Educação Básica, objetivando compreender as principais contribuições e preocupações teóricas dos autores, bem como analisar as estratégias metodológicas adotadas. Para tanto, o texto foi elaborado a partir da análise e do diálogo comparativo entre três pesquisas estruturantes da compreensão da avaliação da aprendizagem como campo de conhecimento, que focam um período de 28 anos (1980 a 2008) (BARRETO; PINTO, 2001; SOUSA, 1994; ULER, 2010), complementadas por duas pesquisas que ressaltam especificidades da área (CANDAU; OSWALD, 1995; SOUSA, 2005).

\section{Avaliação da aprendizagem em foco}

Entre as diferentes modalidades de avaliação, como avaliação de currículo, avaliação de programas e avaliação institucional, a avaliação da aprendizagem constitui o mais frequente objeto de análise dos estudiosos sobre o assunto, sendo esse o principal tema abordado até meados dos anos 1960, uma vez que, no Brasil, somente nos anos 1970 novos objetos de avaliação começam a surgir. Diante desse fato, é indiscutível que há uma grande preocupação dos especialistas em avaliação quanto ao esclarecimento dos significados da avaliação educacional dentro do contexto brasileiro (BARRETO; PINTO, 2001).

As origens dos estudos sobre avaliação da aprendizagem remetem-nos ao início do século XX, período em que, segundo Dias Sobrinho (2003), a avaliação começou a se desenvolver como prática aplicada à educação. Utilizando os conhecimentos da área da psicologia, iniciou-se um movimento que fortaleceu a cultura dos testes e medidas desenvolvido por Robert Thorndike, cujas ideias baseavam-se na mensuração das 
mudanças do comportamento humano. A avaliação buscava a quantificação da aprendizagem, sendo os instrumentos de medição a grande preocupação dos estudiosos, que se dedicavam a investigá-los com grande ênfase na década de 1920. Essa perspectiva psicológica partia do princípio de que o "caminho para a compreensão e aprimoramento da educação escolar é a compreensão do educando” (SOUSA, 1995, p. 44). Dessa forma, a problemática da educação era entendida sob um olhar individual, considerando o desempenho do sujeito algo definido por aspectos biopsicológicos, ignorando as relações com condições sociais, de origem e do próprio sistema escolar (SOUSA, 1995).

A década de 1930 foi marcada pelo avanço das ideias de mensuração, principalmente com Ralph Tyler, que difundiu essa concepção no estudo intitulado Estudo dos oito anos, no qual desenvolveu testes padronizados, escalas de atitude, inventários, questionários, fichas de registro de comportamentos e outras medidas (SAUL, 2001). Seu enfoque avaliativo era conhecido como "avaliação por objetivos", consistindo em determinar em qual grau os objetivos educacionais estavam sendo atingidos pelos programas de currículo e de ensino. Segundo Tyler (1979), os objetivos visavam a produzir modificações no comportamento dos alunos; dessa forma, a avaliação era o processo que determinava o grau em que essas mudanças ocorreram.

A avaliação é, assim, nessa concepção, um valioso instrumento para regulação do conhecimento e das formas de adquiri-lo; mais do que isso, define os comportamentos desejados, controla os seus cumprimentos e aplica as sanções e prêmios correspondentes aos resultados (DIAS SOBRINHO, 2003, p. 19).

O Brasil seguiu a tendência norte-americana baseada no positivismo, de modo que, nos anos finais da década de 1960 e ao longo dos anos 1970, autores brasileiros dedicaram-se a fornecer informações e orientações para o desenvolvimento de testes e medidas educacionais baseadas nos princípios de Tyler (SOUSA, 1995). Além da influência no meio acadêmico, tais ideias, conforme ressalta Saul (2001), traduziram-se 
em leis e decretos federais e estaduais sobre avaliação nas escolas equivalentes ao Ensino Fundamental e médio. No entanto, não foi apenas o Brasil que adotou a concepção para constituição de normas regionais e nacionais de cunho tecnicista; devido ao seu caráter regulatório, essa concepção é, até hoje, amplamente disseminada nas avaliações realizadas no âmbito governamental, em escala mundial.

As ideias de Tyler têm dominado a teoria e o desenvolvimento da avaliação. Sousa (2008) destaca que não se observam ideias alternativas à proposta dele, apenas novas interpretações e avanços, como detalhamento ou explicitação. Nas palavras de Worthen, Sanders e Fitzpatrick (2004, p. 139), a tradição iniciada por Tyler há 60 anos tem mostrado uma força vital impressionante, na medida em que é atraente "deixar que o fato de alcançar objetivos determine o êxito ou o fracasso e justifique melhorias, manutenção ou encerramento das atividades do programa”.

No Brasil, o tema avaliação ganhou força após as reformas educacionais iniciadas na década de 1980, tendo sido alavancado com a Lei de Diretrizes e Bases da Educação Nacional, aprovada em 1996, que determina como incumbência da União a organização da avaliação do rendimento escolar para todos os níveis de ensino.

No início da década de 1980, o Ministério da Educação (MEC) passou a incentivar os estudos sobre avaliação, que, até então, se resumiam em traduções de obras produzidas no exterior que divulgavam ideias e concepções de autores estrangeiros, distantes de nossa realidade, com o objetivo de expandir a cultura sobre o tema. Assim, cresceu a divulgação de periódicos especializados de pesquisas e experiências no campo da avaliação (GOMES NETO; ROSENBERG, 1995).

A década de 1990, com forte impacto na primeira década do século XXI, foi caracterizada pela introdução de políticas educacionais acompanhadas de preocupações com as questões avaliativas, possibilitando o surgimento de vasta literatura especializada que se debruçava na compreensão e intervenção nos processos de avaliação de larga escala e nos sistemas que se espalhavam no país, nos diversos níveis de governo: federal, 
estadual e municipal. O Sistema Nacional de Avaliação da Educação Básica (SAEB), o Exame Nacional do Ensino Médio (Enem), bem como os sistemas estaduais de avaliação que vêm surgindo, constituem experiências avaliativas que contribuíram para a formação e aperfeiçoamento de pesquisadores e técnicos em avaliação de desempenho escolar e institucional e em sistemas de ensino (GATTI, 2002).

\section{Seguindo uma linha do tempo}

No que diz respeito aos estudos sobre o estado da arte da avaliação da aprendizagem na Educação Básica, constata-se que tiveram início com a pesquisa pioneira realizada por Sousa (1994) em sua tese de doutoramento, intitulada Avaliação da aprendizagem: natureza e contribuições da pesquisa no Brasil no período 1980 a 1990.

Com essa tese, inaugurou-se no Brasil uma linha de pesquisa dentro dos chamados estudos do estado da arte, que, até o momento da finalização deste artigo, foi fortalecida pelos estudos realizados por Candau e Oswald (1995), Barreto e Pinto (2001) e Uler (2010). Trata-se de pesquisas que, de uma ou outra forma, apresentam como denominador comum a preocupação com o estágio do conhecimento produzido na área da avaliação educacional, com foco na avaliação da aprendizagem. Como afirmam diversos autores (CASTRO; WERLE, 2004; FERREIRA, 2002; NÓBREGA-THERRIEN; THERRIEN; 2004; ROMANOWSKI; ENS, 2006), esses estudos possuem caráter bibliográfico e permitem organizar e sistematizar criticamente o saber produzido em determinado espaço temporal a respeito de uma área do conhecimento. Ainda, buscam mapear a produção científica, definem as temáticas trabalhadas, as abordagens dominantes, as principais tendências e seus impactos, bem como identificam lacunas, campos inexplorados e questões emergentes que podem ser discutidas em pesquisas futuras.

Analisando a produção científica dentro de uma linha de tempo, verifica-se que os estudos realizados abrangem um período que vai de 
1972 a 2007, tomando como referência de análise basicamente teses de doutorado (SOUSA, 1994, 2005; ULER, 2010), dissertações de mestrado e artigos em periódicos (BARRETO; PINTO, 2001; CANDAU; OSWALD, 1995; SOUSA, 1994, 2005). Uma leitura global torna-se difícil, na medida em que a fonte da produção científica dos trabalhos em questão é bastante diferenciada, porém não é impossível se respeitamos e esclarecemos as especificidades das fontes e tentamos identificar os pontos em comum e as diferenças apontadas pelos pesquisadores.

\section{Superando a visão tecnicista (1980-1990)}

Em sua tese de doutoramento, no intuito de compreender o processo de elaboração e divulgação do conhecimento produzido, Sousa (1994) estudou a produção acadêmica acerca da avaliação da aprendizagem no período de 1980 a 1990, por meio da análise de teses de doutorado e dissertações de mestrado produzidas no país ao longo desses anos. Pode-se afirmar que a autora em questão captou o movimento teórico ocorrido na década de 1980 no campo da avaliação da aprendizagem, defendendo a hipótese de que, nesse período, esforços foram desenvolvidos no sentido de "redirecionar a concepção de avaliação dominante construída sob a influência de Ralph Tyler" (SOUSA, 1994, p. 137).

As dissertações de mestrado e teses de doutorado que serviram de base para esse estudo foram selecionadas a partir de consultas à Associação Nacional de Pós-Graduação e Pesquisa em Educação (ANPEd), ao Inep, ao Conselho Nacional de Desenvolvimento Científico e Tecnológico (CNPq) e às bibliotecas da Faculdade de Educação da Universidade de São Paulo (USP), de Pós-Graduação da Pontifícia Universidade Católica de São Paulo (PUC-SP) e da Fundação Carlos Chagas. Nesse levantamento, foram identificadas 40 pesquisas desenvolvidas em torno da temática da avaliação da aprendizagem, sendo 35 dissertações de mestrado e cinco teses de doutoramento, produzidas em 13 instituições do país durante a década 
de 1980, porém, em decorrência da dificuldade de acesso a elas, a autora realizou a análise de 37 .

Essa pesquisa foi realizada em duas etapas. Na primeira, examinou-se cada um dos estudos coletados, tendo como referência as informações fornecidas pelos próprios autores em relação às seguintes questões: tópicos em que se organiza o trabalho, financiamento, objetivos, finalidades e justificativas do estudo, abordagem teórica, metodologia, resultados, pesquisas sugeridas, teses e dissertações da área citadas na bibliografia. Na segunda etapa, analisaram-se as obras em questão, procurando apreender as características, concepções, ênfases, tendências e contribuições que o conjunto das produções evidenciava, utilizando as seguintes categorias de análise: caracterização geral, eixos temáticos, objetivos/finalidades, abordagem teórico-metodológica, articulação entre as pesquisas e propostas de encaminhamento.

Nela, evidencia-se que a avaliação da aprendizagem não se constituiu como uma temática privilegiada nas pesquisas desenvolvidas na pós-graduação, uma vez que estas corresponderam a 1,3\% do total de pesquisas concluídas no período. A autora constata também que a produção do conhecimento sobre a temática ficou concentrada em quatro universidades: PUC-SP, Pontifícia Universidade Católica do Rio de Janeiro (PUC-Rio), Universidade Federal do Rio de Janeiro (UFRJ) e Universidade Federal do Espírito Santo (UFES), responsáveis por $65 \%$ das pesquisas. Para a autora, essas universidades são "espaços promissores para o florescimento e consolidação da investigação nesta área temática” (SOUSA, 1994, p. 168).

Conforme Sousa (1994), houve predominância de estudos sobre a avaliação da aprendizagem no $1^{\circ}$ grau. Entre os enfoques privilegiados pelos pesquisadores, a preocupação dominante foi quanto à caracterização e análise das práticas avaliativas na escola. Atribui-se esse fato ao movimento de valorização do conhecimento sobre o funcionamento interno da escola que vinha ocorrendo, na década de 1980, no âmbito da pesquisa educacional. Convém destacar que 50\% dos estudos pesquisados adotaram como referencial teórico a concepção tecnicista de 
avaliação, sendo que $40 \%$ dedicaram-se a problematizar essa concepção utilizando, principalmente, as teorias crítico-reprodutivistas. Contudo, esses últimos estudos dedicaram-se mais a denunciar a avaliação como instrumento de legitimação de dado modelo social do que a explorar elementos para sua transformação.

De acordo com a autora, as pesquisas elaboradas no período trouxeram contribuições significativas para a análise sobre como a avaliação vinha sendo vivenciada e revelaram uma tendência de construção de concepções que objetivavam superar a visão tecnicista, engendrando novas perspectivas para a teoria e a prática da avaliação da aprendizagem, tendo como horizonte a construção de uma sociedade mais justa e igualitária (SOUZA, 1994). Essa tendência foi confirmada em outro estudo realizado pela mesma autora (SOUSA, 2005), intitulado 40 anos de contribuição à avaliação educacional, em que buscou analisar as publicações dos pesquisadores da Fundação Carlos Chagas acerca do tema da avaliação educacional, no período de 1972 a 2003.

Nessa pesquisa, ressalta-se que estudos que se dedicaram a realizar uma retrospectiva da produção em avaliação educacional no Brasil apontam que a produção dos anos 1970 e do início da década de 1980 foi respaldada em pressupostos positivistas, que tratam a avaliação como forma de controle do planejamento, sendo uma atividade essencialmente técnica. Sousa (2005) também destaca que essa visão tecnicista foi sendo superada na década de 1980, quando se iniciou um movimento de diferenciação de medida e avaliação.

Outro estudo sobre o estado da arte da avaliação na escola de $1^{0}$ grau foi realizado por Candau e Oswald (1995), tendo como título Avaliação no Brasil: uma revisão bibliográfica. A pesquisa abarcou o período de 1980 a 1992 e, diferentemente de Sousa (1994), que utilizou teses e dissertações para realização do seu estudo, as autoras privilegiaram a análise dos artigos publicados em 11 revistas nacionais, tendo como foco a avaliação na escola de $1^{\circ}$ grau, enfatizando a avaliação na ação pedagógica e buscando colaborar com a "construção de um conhecimento consistente que indique possibilidades e os limites das diferentes opções 
teórico-metodológicas no campo da avaliação" (CANDAU; OSWALD, 1995, p. 26).

A escolha desse período teve por base duas razões: o fato de que, em 1980, se realizou a I Conferência Brasileira de Educação, que, segundo as autoras, constituiu um marco para a reconstrução educacional no país no processo de transição democrática e o entendimento de que, nesse período, estava havendo mudanças no tratamento das questões educacionais, em que os enfoques qualitativos vinham ganhando força (CANDAU; OSWALD, 1995). Por sua vez, os periódicos analisados foram selecionados por serem as revistas mais expressivas na área e por representarem diferentes abordagens na análise das questões educacionais. São eles: Cadernos de Pesquisa, Caderno CEDES, Educação e Seleção, Educação e Sociedade, Em Aberto, Estudos em Avaliação Educacional, Fórum Educacional, Revista Brasileira de Estudos Pedagógicos, Revista da ANDE, Revista de Educação AEC e Tecnologia Educacional. Já os artigos foram escolhidos de acordo com os títulos e classificados em quatro categorias analíticas: tipo de trabalho, enfoque, tema principal e temas correlatos, e tendências pedagógicas e/ou teorias de avaliação.

$\mathrm{Na}$ investigação, ficou evidenciada que as pesquisas analisadas enquadravam-se em dois paradigmas: o quantitativo e o qualitativo. As pesquisas de cunho qualitativo obtiveram menor percentual em relação às de cunho quantitativo, sendo 30 e $70 \%$, respectivamente. Essa distinção constitui um dado muito importante, o qual não tinha sido identificado no trabalho de Sousa (1994).

Quanto ao enfoque privilegiado nas pesquisas, as autoras apontam que a maioria dos artigos científicos discutiu questões relativas a aspectos conceituais, filosóficos e ideológicos da avaliação, seguida daqueles que discutiram aspectos pedagógicos e técnicos (CANDAU; OSWALD, 1995). Nesse tópico, pode-se observar outra diferença em relação à pesquisa de Sousa (1994), cujos resultados apontaram que a preocupação dominante dos pesquisadores dos programas de pós-graduação foi quanto à caracterização e análise das práticas avaliativas na escola. Essa diferença pode ser explicada pelas especificidades do 
material utilizado para análise em cada uma das pesquisas: enquanto Candau e Oswald (1995) utilizaram artigos em periódicos, Sousa (1994) utilizou como referência de análise teses de doutoramento e dissertações de mestrado. Considerando as especificidades da origem das fontes, pode-se afirmar que a utilização de fontes diferentes acaba gerando resultados também diferentes a respeito de um mesmo assunto. Segundo Calderón e Ferreira (2011), as temáticas abordadas em teses e dissertações são definidas a partir de interesses oriundos das inquietações intelectuais vivenciadas pelos pesquisadores na sua vida profissional e intelectual. Dificilmente, nesse tipo de estudo, os mestrandos e doutorandos definem suas temáticas a partir de áreas com maior prestígio no âmbito intelectual. Já os artigos publicados em periódicos científicos, na sua maioria, são estudos realizados por pesquisadores que atuam diretamente no âmbito da produção científica e, dessa forma, são movidos por interesses diferentes, como produtividade, temáticas ascendentes, áreas de maior prestígio, entre outros.

Da mesma forma que a pesquisa de Sousa (1994), o estudo de Candau e Oswald (1995) aponta que a tendência pedagógica tecnicista ainda está presente nos artigos analisados (25,8\%), porém a tendência dialética/transformadora é a que apresentou maior frequência (62,1\%), o que confirma o movimento destacado por Sousa (1994) no sentido da tentativa de construção de novas abordagens que superem a visão tecnicista.

Quanto à temática, as autoras destacaram que houve grande incidência de trabalhos que discutiram a seletividade e o desempenho escolar, evidenciando a preocupação teórica com o fracasso escolar e o papel da avaliação como um dos mecanismos de exclusão social e cultural (CANDAU; OSWALD, 1995). Ainda, a pesquisa em foco permitiu constatar a existência de uma lacuna no campo da pesquisa educacional referente à avaliação da ação pedagógica. Esse fato também foi apontado por Sousa (1994), que ressaltou que a avaliação da aprendizagem não foi um campo explorado nesse período, faltando maior divulgação dos estudos realizados nas universidades sobre o tema. 


\section{Ausência de estudos originais sobre a realidade brasileira (1990-1998)}

Barreto e Pinto (2001) também se dedicaram ao estudo do estado do conhecimento acerca da avaliação na Educação Básica, por meio da pesquisa intitulada Avaliação na Educação Básica (1990-1998), publicada na Série Estado do Conhecimento financiada pelo Inep. Tendo por objetivo analisar as produções acadêmicas sobre avaliação na Educação Básica no período de 1990 a 1998, a pesquisa buscou contribuir para uma visão mais abrangente e elucidadora desse campo de estudo no Brasil.

Diferentemente de Sousa (1994), que pesquisou teses e dissertações, as fontes de pesquisa escolhidas por Barreto e Pinto (2001) foram os periódicos científicos, uma vez que, segundo as autoras, estes apresentam maior peso teórico em torno da produção científica da área e constituem veículos de circulação mais ágil entre pesquisadores e estudiosos do assunto. Entre os periódicos de maior expressão na área, nove foram selecionados: Cadernos de Pesquisa, Educação e Realidade, Educação \& Sociedade, Em Aberto, Ensaio: Avaliação e Políticas Públicas em Educação, Estudos em Avaliação Educacional, Revista Brasileira de Estudos Pedagógicos, Revista da Faculdade de Educação da USP e Tecnologia Educacional, visto conterem artigos que abordam expressamente a questão da avaliação na Educação Básica.

$\mathrm{Na}$ pesquisa, encontrou-se um total de 218 artigos sobre avaliação no ensino básico, sendo que $43 \%$ estavam concentrados na revista Estudos em Avaliação Educacional, 23\%, na revista Ensaio: Avaliação e Políticas Públicas em Educação e 12\%, em Cadernos de Pesquisa. Diante dessa constatação, fica evidenciada a relevância da primeira revista na área, bem como a importância da Fundação Carlos Chagas na contribuição ao tema, uma vez que Estudos em Avaliação Educacional e Cadernos de Pesquisa são publicações da referida fundação. Os anos de 1994, 1995 e 1996 destacaram-se como um período de grande concentração de produções, perfazendo quase a metade do total de artigos selecionados durante os nove anos pesquisados. 
A seleção dos artigos foi feita com base nos títulos, descritores e resumos. Após a leitura do material, foi possível estabelecer quatro categorias de análise: referenciais teóricos e metodológicos da avaliação, avaliação da e na escola, avaliação de políticas educacionais e avaliação de monitoramento, dentro das quais foram arroladas subcategorias. Os artigos analisados foram enquadrados em apenas uma categoria, apesar do fato de que alguns artigos poderiam ser enquadrados em mais de uma delas.

$\mathrm{Na}$ categoria "referenciais teóricos e metodológicos da avaliação", foram identificados 70 artigos, constituindo a categoria mais numerosa. As subcategorias presentes nesse tópico eram: referentes filosóficos, sociais, políticos e pedagógicos; referenciais psicopedagógicos da avaliação; e o núcleo da avaliação dos resultados da aprendizagem. Na categoria "avaliação da e na escola", estavam concentrados os artigos que focavam a avaliação da escola e as realizadas no âmbito desta sob os mais diferentes ângulos. As subcategorias ficaram definidas como: análise das orientações e/ou propostas curriculares; análise de aspectos oficiais ou institucionais da avaliação e suas repercussões na prática escolar; avaliação de alunos com necessidades especiais; avaliação da aprendizagem na escola; avaliação da prática docente; concepções, representações e opiniões de diferentes atores sociais sobre avaliação.

Na categoria "avaliação de políticas educacionais", foram apenas considerados artigos que pudessem ser claramente categorizados como exame de agenda política e de propostas de governo ou como avaliação de programas educacionais. Dessa forma, as subcategorias ficaram assim definidas: avaliação da agenda e das propostas de governo; avaliação de programas educacionais; e impacto dos estudos demográficos na análise das políticas da área. Por fim, na categoria "avaliação de monitoramento" entendida como avaliação padronizada do rendimento escolar dos alunos, realizada no âmbito dos sistemas nacionais ou estaduais de avaliação do ensino básico -, localizaram-se artigos divulgados em apenas cinco dos nove periódicos estudados, sendo Estudos em Avaliação Educacional responsável por $82 \%$ dos 67 textos encontrados. Esse fato demonstra que 
as diversas abordagens sobre o tema não apresentam uma distribuição equitativa nas revistas científicas.

São várias as constatações e tendências apontadas por Barreto e Pinto (2001), das quais se ressaltam cinco. A primeira refere-se à avaliação de monitoramento: embora não seja tratado em diversos periódicos, verifica-se a existência de expressivo número de pesquisadores que vêm estudando o tema há mais de dez anos, o que sugere que esse campo de estudo está em processo de consolidação. O segundo ponto diz respeito ao fato de existirem muitos artigos com transcrições de ideias, experiências e reflexões produzidas no exterior, revelando uma ausência de estudos originais sobre a realidade brasileira.

O terceiro ponto refere-se à constatação de elevado número de artigos sobre ideias, concepções, teorias e pressupostos da avaliação, se comparado com o volume de artigos sobre o âmbito escolar, fato que sugere a preocupação dos estudiosos brasileiros com o esclarecimento dos significados da avaliação, bem como indica uma lacuna, no âmbito das revistas científicas, no que diz respeito aos trabalhos voltados para a realização de intervenções intencionais na escola por parte dos mais variados agentes educacionais. Entretanto, em relação a essa lacuna, convém mencionar que se trata de um vazio específico da fonte analisada, isto é, revistas científicas, na medida em que a pesquisa de Sousa (1994), abordando o período de 1980 a 1990, destaca como tendência a predominância, nas dissertações de mestrado e teses de doutorado, de estudos relacionados com a caracterização e análise das práticas avaliativas no universo escolar.

Um quarto ponto a ser destacado diz respeito aos estudos de "avaliação de monitoramento", nos quais foi possível observar a predominância do discurso do poder público, como também as discussões que giraram em torno do accountability, ou seja, da importância da informação que o serviço público deve dar à população, a mesma que deve servir para orientação de ações voltadas aos sistemas de ensino. Para finalizar, o quinto ponto refere-se à coexistência de discursos teóricos paralelos que não dialogam entre si: um que se reporta à avaliação processual/formativa do ensino e outro voltado para a avaliação de resultados, tratando-se 
de visões teóricas que sustentariam o paradigma emancipatório e o paradigma tecnicista-tradicional, respectivamente.

\section{A construção de uma proposta emancipatória (2000-2007)}

Dando continuidade às pesquisas do estado da arte na área da avaliação da aprendizagem, Uler (2010), em sua tese de doutoramento intitulada Avaliação da aprendizagem: um estudo sobre a produção acadêmica dos Programas de Pós-Graduação em Educação (PUCSP, USP, UNICAMP), assim como Sousa (1994), utilizou como fontes de pesquisa as teses e dissertações, buscando compreender a concepção de avaliação da aprendizagem veiculada pelos Programas de Pós-Graduação em Educação em três universidades: PUC-SP, USP e Universidade Estadual de Campinas (Unicamp), no período de 2000 a 2007.

A escolha dessas três universidades justificou-se pela relevância que apresentam no estado de São Paulo em relação à produção científica sobre o tema e pelos intelectuais de referência no campo da avaliação que abrigam, como Ana Maria Saul, Mere Abramowicz, Isabel Cappelletti e Clarilza Prado de Sousa, na PUC-SP, Sandra Zákia Lian Sousa e Celso dos Santos Vasconcelos, na USP, Luiz Carlos Freitas e José Dias Sobrinho, na Unicamp. Já a escolha do período deve-se ao fato de se considerar que, por ser uma nova década, possa ter havido avanços em relação à avaliação da aprendizagem, considerando outros estudos anteriores sobre a temática, já citados neste artigo (BARRETO; PINTO, 2001; SOUSA, 1994).

Para a seleção das teses e dissertações, consultaram-se as bibliotecas das universidades em questão, bem como se realizou um levantamento no banco de teses e dissertações da Coordenação de Aperfeiçoamento de Pessoal de Nível Superior (CAPES). Para realizar essa pesquisa, Uler (2010) manuseou cada uma das teses e dissertações estudadas, uma vez que seus resumos não possuíam todos os elementos elucidativos, fato destacado pela autora como uma das grandes dificuldades encontradas. Ao todo, foram selecionados 37 estudos sobre o tema avaliação da 
aprendizagem nas universidades mencionadas, tendo sido organizados, para melhor análise dos trabalhos, estudos analíticos focados nos seguintes itens: identificação, objetivos, abrangência, metodologia e principais contribuições. Da mesma forma, foram elaboradas categorias de análise, formuladas a partir da leitura das pesquisas: avaliação da aprendizagem na progressão continuada e nos ciclos, avaliação da aprendizagem de políticas públicas e avaliação da aprendizagem nas práticas escolares. Assim como Sousa (1994), Uler (2010) aponta que a maioria das pesquisas realizadas foi voltada ao Ensino Fundamental, porém revela preocupações com a avaliação da aprendizagem no Ensino Médio.

Das 17 pesquisas inclusas na categoria "avaliação da aprendizagem na progressão continuada e nos ciclos", dez revelaram que não houve efetivação das mudanças propostas pelas políticas de progressão continuada, sendo que ainda permanecia nas escolas a concepção positivista de avaliação. Esse fato também é apresentado por Sousa (1994) em sua pesquisa, na qual se detectou que $50 \%$ dos estudos analisados possuíam uma concepção tecnicista de avaliação. Os outros sete trabalhos consideraram que o sistema de progressão continuada é bom e possui visão formativa de avaliação.

Na categoria "avaliação da aprendizagem de políticas públicas", cinco trabalhos destacaram o Enem, o SAEB e o Sistema de Avaliação do Rendimento Escolar do Estado de São Paulo (SARESP). A autora destaca que, a partir desses trabalhos, é possível concluir que "a regulação avaliativa vincula-se a projetos hegemônicos de sociedade" (ULER, 2010, p. 131). A respeito desse sistema de avaliação de larga escala, Barreto e Pinto (2001) destacam que os estudos sobre os sistemas de aferição encerram-se em si mesmos, não havendo esforço de articulação com estudos sobre escola e rendimento escolar.

Dos 15 trabalhos enquadrados na categoria "avaliação da aprendizagem nas práticas escolares", dez apontam "uma caminhada em busca da avaliação formativa, emancipatória, participativa” (ULER, 2010, p. 132). Um dado importante a ser destacado refere-se ao fato de que a PUC-SP foi responsável por $51,4 \%$ dos trabalhos investigados nessa 
pesquisa, dado que reafirma a tese de Sousa (1994, p. 168), para quem essa universidade constituía "espaço promissor para o florescimento e consolidação da investigação nesta área temática".

A pesquisa de Uler (2010) destaca que os autores dos estudos pesquisados utilizaram autores nacionais e estrangeiros, o que indica uma mudança, uma vez que Barreto e Pinto (2001), ao estudar o período de 1990 a 1998, evidenciaram a predominância de referenciais estrangeiros, fato que revelava ausência de estudos originais da realidade brasileira. Ademais, o ponto mais relevante da pesquisa em questão é a evidência de que, em termos teóricos, apesar de ainda existirem resquícios do pensamento positivista, há a predominância de um movimento de reflexão, no ambiente universitário, voltado à hipervalorização dos aspectos relativos à chamada avaliação emancipatória, como alternativa aos modelos tradicionais e tecnicistas. Esse fato contrasta com a realidade identificada nas pesquisas de Sousa (1994) e Barreto e Pinto (2001), nas quais ficou evidenciada a predominância da concepção tecnicista de avaliação nos trabalhos pesquisados.

\section{Conclusões}

Por meio da linha do tempo referente às pesquisas que tratam de uma forma ou outra da avaliação da aprendizagem, podem-se destacar alguns pontos da trajetória desse campo de estudos no país.

Fica evidenciado pelas pesquisas apresentadas que, nas décadas de 1970 e 1980, o paradigma tecnicista tinha grande força nas produções acadêmicas, evidenciando a visão positivista de avaliação. No decorrer da década de 1980, apesar do tecnicismo ainda exercer grande influência no campo da avaliação, observaram-se esforços no sentido de superar essa visão na direção de propostas mais formativas. É importante ressaltar que, nesse período, a grande preocupação dos pesquisadores era quanto à caracterização das práticas avaliativas na escola. Já na década de 1990, a preocupação dos pesquisadores deslocou-se das práticas avaliativas na 
escola para o esclarecimento quanto às questões sobre ideias, concepções, teorias e pressupostos da avaliação.

Nesse período, também se destacou a ausência de referenciais teóricos de origem brasileira relativos à avaliação, sendo a maioria dos referencias presentes nas produções acadêmicas de autores estrangeiros. No entanto, constata-se que essa questão é superada no período de 2000 a 2008, uma vez que a pesquisa de Uler (2010) ressalta que, nos trabalhos investigados, há referenciais teóricos nacionais e estrangeiros. Finalmente, é possível observar a construção de um movimento teórico que acenava para a hegemonia de uma abordagem emancipatória e participativa no campo da avaliação da aprendizagem.

\section{Referências}

BARRETO, E. S. S.; PINTO, R. P. Avaliação na Educação Básica (1990-1998). Brasília, DF: MEC/Inep/Comped, 2001.

BRASIL. Lei n. 9.394, de 20 de dezembro de 1996. Estabelece as diretrizes e bases da Educação Nacional. Diário Oficial da União, Brasília, DF, 23 dez. 1996. Disponível em: <http://www.planalto.gov.br/ccivil_03/leis/19394.htm>. Acesso em: 30 ago. 2013.

CALDERÓN, A. I.; FERREIRA, A. G. Administração da educação no Brasil: um diálogo comparativo com as tendências temáticas da Revista Ibero-Americana de Educação. RBPAE, v. 27, n. 2, p. 321-339, maio/ago. 2011.

CANDAU, V. M.; OSWALD, M. L. M. B. Avaliação no Brasil: uma revisão bibliográfica. Cadernos de Pesquisa, n. 95, p. 25-36, nov. 1995.

CASTRO, M. L. S.; WERLE, F. O. C. Estado do conhecimento em administração da educação: uma análise dos artigos publicados em periódicos nacionais 1982-2000. Ensaio: Avaliação e Políticas Públicas em Educação, v. 12, n. 45, p. 1045-1064, out./dez. 2004. 
DIAS SOBRINHO, J. O campo da avaliação: evolução, enfoques, definições. In: DIAS SOBRINHO, J. Avaliação: políticas educacionais e reformas da educação superior. São Paulo: Cortez, 2003. p. 13-52.

FERREIRA, N. S. A. As pesquisas denominadas "estado da arte". Educação e Sociedade, v. 23, n. 79, p. 257-272, ago. 2002.

GATTI, B. A. Avaliação educacional no Brasil: pontuando uma história de ações. EccoS Revista Científica, São Paulo, v. 4, n. 1, p. 17-41, jun. 2002.

GOMES NETO, J. B.; ROSENBERG, L. Indicadores de qualidade do ensino e seu papel no Sistema Nacional de Avaliação. Em Aberto, v. 15, n. 66, p. 13-28, abr./ jun. 1995.

NÓBREGA-THERRIEN, S. M.; THERRIEN, J. Trabalhos científicos e o estado da questão: reflexões teórico-metodológicas. Estudos em Avaliação Educacional, v. 15, n. 30, p. 5-16, jul./dez. 2004.

ROMANOWSKI, J. P.; ENS, R. T. As pesquisas denominadas do tipo "estado da arte” em educação. Diálogo Educacional, v. 6, n. 19, p. 37-50, set./dez. 2006.

SAUL, A. M. Incursionando pela teoria da avaliação educacional. In: SAUL, A. M. Avaliação emancipatória: desafios à teoria e à prática de avaliação e reformulação de currículo. 6. ed. São Paulo: Cortez, 2001. p. 25-52.

SOUSA, C. P. (Org.). Avaliação do rendimento escolar. 15. ed. Campinas: Papirus, 2008.

SOUSA, S. Z. L. Avaliação da aprendizagem: natureza e contribuições da pesquisa no Brasil no período de 1980 a 1990.1994. 194 f. Tese (Doutorado em Educação) — Universidade de São Paulo, São Paulo, 1994.

SOUSA, S. Z. L. Avaliação da aprendizagem nas pesquisas no Brasil de 1930 a 1980. Cadernos de Pesquisa, São Paulo, n. 94, p. 43-49, ago. 1995.

SOUSA, S. Z. L. 40 anos de contribuição à avaliação educacional. Estudos em Avaliação Educacional, v. 16, n. 31, p. 7-36, jan./jun. 2005. 
TYLER, W. R. Princípios básicos de currículo e ensino. 6. ed. Porto Alegre: Globo, 1979.

ULER, A. M. Avaliação da aprendizagem: um estudo sobre a produção acadêmica dos programas de pós-graduação em educação. 2010. 237 f. Tese (Doutorado em Educação) — Pontifícia Universidade Católica de São Paulo, São Paulo, 2010. WORTHEN, B. R.; SANDERS, J. R.; FITZPATRICK, J. L. Avaliação de programas: concepções e práticas. São Paulo: Gente, 2004.

Recebido: 29/11/2010

Received: 11/29/2010

Aprovado: 28/06/2011 Approved: 06/28/2011 